\title{
Cultural Regression and Aesthetic Analysis in Traditional Music Teaching
}

\author{
Linlin Jin \\ Medical Technology Department, Zaozhuang Vocational College of Science \& Technology , Tengzhou \\ Shandong, China \\ 327826097@qq.com
}

Keywords: traditional music teaching; culture; aesthetics; sentiment; truth, goodness and beauty

\begin{abstract}
The combination of Chinese traditional music and extensive culture has formed a Chinese traditional music culture with Chinese characteristics. In the continuous transmission of music culture, its foundation rather remains unchanged. The foundation of this music culture makes it make continuous progress to get real inheritance and development. Culture is the ideological connotation of music, the traditional music teaching must return to the cultural ontology. Without the support and nourishment of culture, music will have no theme and soul, and become the shell of sound. Culture is referred as a way and attitude of life, which is an important content of music. Culture exists in people's life, it is the realistic object of music reflection. Reflecting life, serving life and promoting life are regarded as the important missions of music. In the aesthetic process of music, everyone shares the beauty and joy of life. In the study of songs, the theme of truth, goodness and beauty should be closely adhered to, the space-time effect of music should be enhanced, the aesthetic feelings of students should be aroused, and they should be nurtured and educated by truth, goodness and beauty. To give music into full play, influence the aesthetic function of students, cultivate students' beautiful sentiment and pure quality, the paper hopes to realize the return of traditional music teaching in culture, enhance the aesthetic experience of music teaching.
\end{abstract}

\section{Introduction}

Music and related culture are organically integrated. Music and its teaching cannot be carried out in isolation from culture. It is necessary to restore the process of music teaching to a process of cultural infiltration, which truly embodies the ideological core of "music is culture or music contains culture". Therefore, music teaching should deal with the relationship between musicality and culture, and culture should be integrated and permeated into musicality. Just as Chinese teaching should deal with the relationship between instrumentality and humanism, mathematics teaching should deal with the relationship between the taste of mathematics and the taste of life, and music teaching should also deal with the relationship between musicality and culture ${ }^{[1]}$.

The Standard of Music Curriculum (2017) clearly points out: "Music and related culture are the concentrated embodiment of the humanities attribute of music class and the learning field that directly enhances the students' cultural literacy." It helps to expand students' musical cultural horizons, promote their experience and feelings of music, and enhance their ability to appreciate, express, create and appreciate music ${ }^{[2]}$. "Music teaching is not a professional music training. Music and its teaching cannot be carried out in isolation from culture. It is necessary to restore the process of music teaching to a process of cultural infiltration. As Elliott emphasizes in his book, "the essence of music is contextual, social, and even political. It cannot be separated from the actual musical context, social culture or even political system." Religious beliefs, individual emotions and independent existence, only acknowledge the subtle role of these factors, it is the normal practice of today's life. "In short, music and related cultures are organically integrated. Without culture, music is like fish leaving water, and music teaching becomes dry skill training. "Music education becomes a pure technical operation suspended on the surface." Its educational value will be lost ${ }^{[3]}$.

The connotation of "music aesthetics" is clearly defined as: music aesthetics refers to the 
experience, perception, communication, communication and cognition of different musical cultural contexts and humanistic connotations to the aesthetic sense of music art. This definition has the brand of Chinese traditional culture and is closely related to the development of modern aesthetic education thought. With the further study of modern aesthetic education theory, the idea of music aesthetic education has been expanded continuously. The aesthetic education concept after 1980s is different from the aesthetic education in the early stage of school music education in our country, which proposed from the perspective of the integrity of modern education. Chinese traditional music was formed in the early farming era. With the continuous progress of society, traditional music has been passed on, and has been fully developed in the fusion of various ethnic music and foreign music, which is also the result of the continuous progress of Chinese civilization. In traditional music teaching, culture and aesthetics are combined together, and Chinese traditional music combines with extensive and profound culture to form Chinese traditional music culture with Chinese characteristics, which plays an important role in the progress of human culture. In the study of songs, the theme of truth, goodness and beauty should be closely adhered to, the space-time effect of music should be enhanced, the aesthetic feeling of students should be aroused, the edification and education of truth, goodness and beauty should be brought into full play, and the functions of music, such as moisturizing and silent education, should be brought into full play. This paper combines the thought of music itself with the traditional culture in a natural way to realize the cultural regression and aesthetic experience in the traditional music education ${ }^{[4]}$.

\section{Cultural connotation in Chinese traditional Music}

Chinese traditional music combines with extensive and profound culture. Chinese traditional music culture pays attention to the form of performing in harmony between nature and man, combines the thought of music itself with the traditional culture in a natural way. In the traditional culture gradually progress and development. Chinese traditional music was formed in the early farming era. With the development of society and the progress of culture, the traditional music was developed, and the music of various nationalities and foreign music were merged together and developed fully ${ }^{[5]}$. This is also the result of the continuous progress of our civilization. Traditional music refers to the music which is created by the Chinese people with the inherent form of their own nation using the inherent method of their own nation. It includes not only the ancient works produced in history, but also the contemporary works. Traditional music gathers the music ideal and wisdom of each nationality of our country, and has a unique cultural and historical background, so it can stand steadily in the world music forest. Social scholars in the definition of traditional music, although there are certain differences in wording, but are the same way. That is, Chinese traditional music is the product and deposition of history and culture, the result of the fusion and mutual influence of the cultures of all nationalities, and the development of Chinese traditional music under the continuous progress of history and the influence of foreign cultures, so it has a distinct character of the times ${ }^{[6]}$.

\subsection{Traditional music has distinct epochal and regional differences}

As the main feature of Chinese traditional music culture, the characteristics of traditional music culture are different in different periods. The emergence, innovation and development of Chinese traditional music are developed gradually with the progress of specific historical period. Each kind of music has a specific historical mark, a specific cultural region as the basis and background, as well as the contributions of various ethnic artists. In the end, traditional music releases rich historical and cultural color in the performance of modern society ${ }^{[7]}$. The regional difference of Chinese traditional music culture is another remarkable feature, which is mainly expressed in space. In the same historical period, a certain music form in different regions will also have different characteristics. The reason for this regionality is that only when a certain form of music is integrated with local customs, living, culture and religion, it can cater to the aesthetic concepts of the local people, and it can continue to progress and develop healthily. Finally, the same type of music differentiated into regional music varieties. For example, Yiyang culture is unique, with a 
long history, with a strong flavor of Chu culture. In particular, Yiyang local traditional music has a profound cultural heritage and rich forms of expression. Yiyang local music can be traced back to the Chu State in the Spring and Autumn and warring States period. In the vast territory, the people of all nationalities sing loud and powerful folk songs and various traditional music, and vast grasslands, majestic mountains, galloping horses, hovering eagles, flocks of sheep.

\subsection{Commonness and compatibility of traditional Chinese music culture}

The commonness of traditional music culture is also called commonality, which is expressed as the characteristic within the scope of cultural attribute, which has extensive and far-reaching influence on the progress and development of traditional music. For example, in the formation of traditional music culture, the influence of the same social factors makes the traditional music culture have similar social functions, and then the historical culture of a specific period is reflected in the Chinese traditional music culture. The more influential Confucianism and Taoism have great influence on the formation and development of Chinese folk art. The compatibility of Chinese traditional music culture refers to inheritance and variability. The inheritance of traditional music culture is the environment and condition of its existence and steady development. In the continuous transmission of music culture, its own foundation is invariable, this kind of music culture foundation makes it get the real inheritance and development in the continuous progress. However, the variation of the traditional music culture is mainly the characteristic of the times with the progress of history. Only by adapting to the changes of the times and people's aesthetic concepts, can the traditional music culture survive. The compatibility of this kind of culture is very important for the development of traditional music culture, because only true compatibility can make traditional music invincible ${ }^{[8]}$.

\section{The two wings of music teaching: musicality and culture}

Music and related culture are integrated organically. Music teaching should deal with the relationship between musicality and culture, and culture should be integrated and permeated into musicality. Traditional music teaching is not professional music training. Music and its teaching cannot be carried out in isolation from culture, traditional music teaching cannot be separated from the concrete and true musical context, social culture and even political system, religious belief, personal emotion and independent existence. Music and related culture are organic, without culture, music is like fish without water, music teaching will become dry skills training.

\subsection{Culture is the background of music}

Culture is the background knowledge of music (background of times, background of creation, background of theme). Lack of necessary background knowledge, students cannot really understand the meaning of music works. Music art does not exist in isolation, it is closely related to the era, historical background, creators' source of creation and relevant cultures in various regions. In fact, any kind of music is above all the product of a particular culture, it itself is defined by culture, without culture, music becomes a source of water, no wood. In short, in order to understand and grasp the connotation and meaning of musical works accurately and deeply, we must master the culture and history related to music.

\subsection{Culture is the ideological and emotional connotation of Music}

Culture is referred as the thought (emotion) connotation of music, without the support and nourishment of culture, music has no theme and soul, and becomes the empty shell of sound. Music is a sound in form (musical-organized voice) and a culture in content, reflecting human emotion and spirit. Music has its own way of expression and thinking, which is also the content and expression of music culture. All music is used for expression, this feeling and meaning is the meaning and culture of music. For example, appreciation of the Yellow River Boat Song, when the students understand the long history of the Yellow River, see the magnificent landscape, will inevitably increase the students' emotional experience of music. The students listened to the high-spirited 
"Yellow River Boat Song", watched the picture of the boatmen wrestling with the wind and waves, recited the passionate poems, the rich culture activated the emotion of the music, and the students seemed to be in the middle of the rolling torrent, moved by the grandeur of the Yellow River.

\subsection{Culture is a kind of life, and the content of music}

One of the important characteristics of culture is living life. Culture exists in people's life. Culture is the realistic object of music reflection. It is the important mission of music to reflect life, serve life and promote life. Music teaching must return to life, to the real world and objective things that music expresses and reflects. Without life and objective objects, it is impossible to understand the connotation of music deeply and accurately. Art originates from life and is higher than life. Mongolian music illustrates this very well. While studying the song of Nadam, let students know that the Nadamu Congress is an annual traditional festival for the Mongolian people. The contents of the conference are mainly wrestling, horse racing, archery, Sabre, horse set, Mongolian chess and other traditional national events, students can well understand the songs lively, compact tunes, neat and sharp style characteristics.

\section{Cultural return of traditional music teaching}

Music itself is also a kind of culture, music is a kind of knowledge symbol system with its own characteristics. In the mode system, it is not only the relationship between pitch and pitch, but also the relationship between melody and interval. At the same time, it is processed in terms of length, composition of rhythm, rhythm system, and selected by tone quality, tone color and so on. By mastering and using its color, strength, speed and so on, the general system of "music sound", which is formed by processing, becomes the material of music art. This is the cultural characteristic of music itself. From the point of view of music teaching, the focus of the relationship between culture and music is music, culture serves music, music teaching must always adhere to music, students can not only learn music in the meaning of language and culture. It must be done through music. Music is the nature of music teaching, culture must permeate into the activities of music.

The music class is cultural, but it cannot become a culture class. The primary task and core task of the music class is music. The first thing we should do is to cultivate students' sense of music, to listen to the music literacy created by singing and playing, and to emphasize the cultural nature. But we can't go to extremes, we can't cultivate "oral revolutionaries," we can only talk about the truth or culture of a bunch of music, but when we sing, the tune is out of tune, the five sounds are not complete, the rhythm is uneven, and the strong and weak beat is inverted. Whether it is singing or playing music, the most basic requirements to achieve, that is, sing out the song, played out the music, song and music pitch, rhythm, strong and weak, slow and fast, the tone to sing accurately in place. Therefore, music lessons should have the characteristics of music lessons, adhere to music-based, pay attention to music ontology, let music lessons return to the origin of music. Starting with music, the students should be guided to grasp the form of musical expression as a whole, understand the role of musical elements in music, pay attention to the basic skills of music, and embody musicality.

Comparatively speaking, musicality is a dominant existence, culture is a recessive existence, musicality is the main line of music teaching, and culture is the auxiliary line of music teaching. Music is art, and culture is learning. Art is the perceptible, touchable, and learning is the Tao behind it. In short, a successful music class, culture and music is indispensable, culture should be integrated and permeated into musicality.

\section{Conclusions}

The development of Chinese traditional music combines with the development of the times, customs, religious beliefs and cultures in a specific historical period, and forms the unique cultural characteristics and connotations. The subject synthesis of music course should be taken based on music, that is, on the premise of keeping the characteristics of music subject, choosing the 
appropriate content, implementing the comprehensive teaching of subject infiltration, and strengthening the understanding of music more deeply through synthesis. To guide students to fully feel the joy brought by music, but also to guide students out of the shallow aesthetic limitations, try to understand the artistic conception that the composer wants to express, so that the students' emotion and the author's emotion can be combined beyond time and space. To sublimate the music content, connotation and scene, make the music classroom return to the true understanding of the music itself, and realize the cultural regression of the traditional music teaching and the promotion of the aesthetic value.

\section{References}

[1] Yang Minkang."Non-posthumous" Protection should return to "Grass-Roots consciousness" -On the value and status of traditional Music in Intangible Cultural Heritage [J]. People’s Music,2009, (11):24-28.

[2] Liu Ni. On the return and continuation of traditional Music Culture from the rise of Ancient style Music [J]. Home Drama,2015, (22):68-71.

[3] Wang Zheng. Some views on the implementation of Multicultural Music Education [J]. Journal of Changchun University of Technology. 2012, 45(11) :56-59.

[4] Liu Guizhen. The Times Strategy of the Development of Chinese Multicultural Music Education [J]. Journal of Northeast normal University (philosophy and Social Science Edition).2012(02):38-42

[5] Wen Hongqing. The role of News Communication in the Promotion of Ancient Music [J]. News front, 2015(24):42-45.

[6] Tan Mengqian. The reference and Development of Ancient songs to Classical Literature and Art [J]. Literature education, 2017(09):31-35.

[7] Yao Tingting. An Analysis of the types of Ancient Chinese Music [J]. Folk music,2016(03):32-34.

[8] Wang Aiping. Looking for the "whole self" in singing-the awakening of conscious national cultural consciousness from ancient style music [J]. Journal of Anyang normal University.2014(3):45-49. 